\title{
USO DE SERICINA DE BOMBYX MORI NO PREPARO DE BIOMATERIAIS COMBINADOS COM QUITOSANA E ALGINTATO
}

\author{
E. G. RAPHAEL ${ }^{1}$, A. P. SONE ${ }^{1}$ e M. L. GIMENES ${ }^{1}$ \\ ${ }^{1}$ Universidade Estadual de Maringá, Departamento de Engenharia Química \\ E-mail para contato: marcelino@deq.uem.br
}

\begin{abstract}
RESUMO - Este trabalho apresenta um estudo sobre preparação de filmes/membranas da blenda da proteína sericina com os biopolímeros alginato e quitosana, pela técnica de casting, com o uso de agentes plastificante e reticulante. Investiga-se as propriedades desses filmes/membranas, como o aspecto visual, sendo continuidade, homogeneidade e manuseabilidade, e o teor de umidade das variações dos filmes/membranas produzidos. A utilização dos agentes confere aos mesmos um aspecto agradável, sendo contínuos, homogêneos, flexíveis, e manuseáveis, e a formulação que apresenta o menor valor de umidade é a blenda sericina e alginato, sendo de $20,9 \%$.
\end{abstract}

\section{INTRODUÇÃO}

As embalagens derivadas do petróleo são largamente produzidas e utilizadas, devido ao baixo custo de produção, às boas propriedades mecânicas e de barreira. Por outro lado, não são biodegradáveis, ou seja, há um grave problema no momento do descarte, sendo nocivos ao meio ambiente. A confecção de polímeros sintéticos e sua introdução no mercado trouxe grandes benefícios, principalmente no setor de embalagens, de grande importância no setor alimentício e outros produtos perecíveis, por serem hidrofóbicos e biologicamente inertes. Uma grande vantagem é a substituição do vidro e das embalagens metálicas (Scott, 2000). Com isso, são amplas as pesquisas por materiais biodegradáveis provenientes de fontes renováveis que substituam os materiais utilizados atualmente e que atendam as demandas ambientais.

Dentre as macromoléculas que permitem a elaboração de biofilmes, destaca-se a sericina, que é um resíduo gerado no processo de produção dos fios de seda, cuja recuperação e aproveitamento poderiam representar uma economia significativa, um benefício social e uma solução ao impacto ambiental causado por efluentes não tratados e resíduos sólidos (Zhang, 2002; Wu et al., 2007). A seda produzida pelo bicho-da-seda possui a vantagem de ser um recurso natural renovável disponível no Brasil e possuir um custo relativamente baixo.

O casulo do Bombyx mori (bicho-da-seda) é o produto da sericultura, utilizado para a produção dos fios da seda. No processo de degomagem, a sericina é o resíduo, assim como os casulos classificados como inadequados para produção de seda. A sericina compõe cerca de 20-30\% 


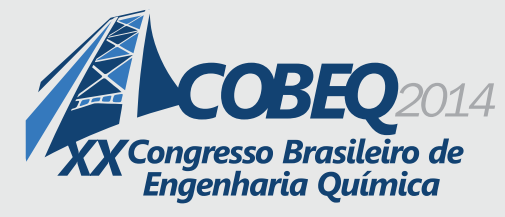

da massa do casulo. É uma proteína globular com alta massa molecular, hidrofílica, solúvel em água quente. A recuperação da sericina pode agregar valor ao resíduo, que pode ser uma fonte natural para o desenvolvimento de novos materiais compostos e biodegradáveis.

A sericina é uma proteína natural, têm excelentes propriedades antioxidantes, antibacterianas, resistência UV e resistência à umidade. Hoje, é utilizada em diversas aplicações como cosméticos, membranas, suportes para enzimas imobilizadas, suplemento alimentar, matéria-prima para medicamentos, e fibras funcionais (Kongdee et al., 2004).

As blendas poliméricas constituem-se na mistura (física ou mecânica) de pelo menos dois polímeros, de forma que só exista interação intermolecular secundária entre as cadeias moleculares dos polímeros, sem que haja reação química entre os mesmos. Existem duas formas tradicionais de se obter blendas poliméricas: sob temperatura suficientemente alta para fundir os polímeros sem causar degradação dos mesmos, ou dissolvendo os polímeros em um solvente comum a ambos, sendo o solvente evaporado posteriormente (Wiebeck e Harada, 2005). Através da formação de blendas poliméricas é possível obter uma sinergia das propriedades individuais de cada material, além da possibilidade de melhorar ou controlar suas propriedades mecânicas finais devido à interação entre as estruturas químicas.

O alginato é um polissacarídeo de cadeia linear obtido da parede celular de algas marinhas marrons e bactérias, e é responsável por promover rigidez e flexibilidade às mesmas. Corresponde à até $40 \%$ da massa seca de algas marinhas marrons na forma de sais de cálcio, magnésio, sódio e potássio. A maioria dos alginatos é extraída de algas colhidas de seu habitat natural, uma vez que o seu cultivo é muito caro, o que inviabilizaria sua aplicação industrial (Rinaudo, 2008). O alginato é insolúvel em água à temperatura ambiente, sendo o preparo de sua solução um pouco complicado. Ele deve ser disperso em água, sob alta taxa de agitação ou com aquecimento. Devido à sua estrutura linear e elevada massa molecular, o alginato é capaz de formar filmes resistentes e boas fibras no estado sólido (Rinaudo, 2008). O alginato possui facilidade em formar gel, sendo capaz de reter grande quantidade de água. A formação deste gel é independente da temperatura, o que faz com que este biopolímero seja utilizado na maioria das vezes sob esta forma. É um material muito utilizado como agente espessante e estabilizante em alimentos, e também na produção de adesivos, tintas, brinquedos e papéis (Oliveira, 2004). $\mathrm{Na}$ área biomédica, o alginato possui algumas características vantajosas como biocompatibilidade, não toxicidade, hidrofilicidade e capacidade de formar gel.

A quitosana é obtida pela desacetilação da quitina, encontrada nas paredes celulares de fungos e exoesqueletos de insetos e crustáceos. A quitosana é um produto natural, de baixo custo, renovável e biodegradável, de grande importância econômica e ambiental. As carapaças de crustáceos são resíduos abundantes e rejeitados pela indústria pesqueira, que em muitos casos as consideram poluentes. Assim, o impacto ambiental causado pelo acúmulo dessas carapaças é diminuído. As principais e mais conhecidas áreas de aplicação da quitosana são na indústria alimentícia, cosmética, biofarmacêutica e biomédica, mas também na agricultura e tratamento de água. A quitosana apresenta atividade antimicrobiana, atoxicidade, biocompatibilidade e biodegradabilidade. Os filmes de quitosana têm permeabilidade molecular seletiva e esta é afetada 


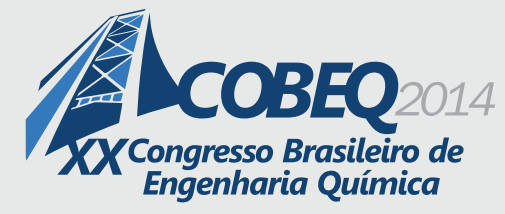

pela espessura do mesmo, pelo grau de desacetilação, massa molar e grau de molhabilidade (Chen $\mathrm{X}$ et al., 2002).

Para a produção de biofilmes à base de sericina é necessária a incorporação de um agente plastificante que os torne menos quebradiços, sendo indicados para este fim os polióis (p.ex. glicerol e sorbitol). Plastificante é uma substância que, adicionada a um material polimérico, modifica as propriedades do mesmo, com o intuito de melhorá-las. Essas propriedades modificadas podem ser: processabilidade, flexibilidade, módulo de elasticidade, dureza, viscosidade do material fundido e temperatura de transição vítrea (Rabello, 2000). A ação dos plastificantes em filmes poliméricos baseia-se na diminuição das forças intermoleculares, provocando a separação entre as macromoléculas do polímero e aumentando assim a mobilidade de suas cadeias, melhorando as propriedades mecânicas, como a flexibilidade (Zactiti, 2004).

A adição de um agente reticulante é outra forma de melhorar as propriedades dos biofilmes à base de sericina, aumentando o grau de reticulação da matriz polimérica. A literatura científica relata numerosas aplicações de polímeros naturais (goma arábica, amido, quitosana, dextrana, sulfato de condroitina, pectina, alginato, gelatina, sericina, etc.). Entretanto, a utilização dos mesmos é limitada devido à alta solubilidade em água. A reticulação térmica em muitas situações não é adequada quando comparada à reticulação química. Temperaturas elevadas por longos períodos de tempo para o crosslinking térmico geralmente melhoram o grau de reticulação, mas as membranas ficam quebradiças. Além disso, o tratamento com excesso de calor pode conduzir à desnaturação ou decomposição de alguns dos componentes da proteína (Gimenes et al., 2007). O agente reticulante dimetiloluréia (DMU) mostrou ser um agente adequado, devido ao fato de a reticulação ocorrer principalmente por meio dos grupamentos hidroxila do polímero.

\section{MATERIAIS E MÉTODOS}

\subsection{Materiais}

Os casulos utilizados nas extrações foram cedidos pela empresa BRATAC S/A. Para a confecção dos filmes, as macromoléculas utilizadas foram a proteína sericina obtida a partir dos casulos do bicho da seda Bombyx mori, o alginato de sódio P.A. (Dinâmica) e a quitosana com grau de desacetilação 86,3\% (Polymar). Ácido acético P.A. (Nuclear) foi utilizado para solubilizar a quitosana. Dimetiloluréia (DMU) (Sigma-Aldrich) foi utilizado como agente reticulante destes materiais e glicerol P.A. (Química Moderna) como agente plastificante. Nos dessecadores utilizados para o armazenamento dos filmes a 52\% UR foi adicionada solução saturada de nitrato de magnésio (J.T. Baker).

\subsection{Métodos}

Obtenção da solução de sericina: a sericina foi extraída dos casulos que foram cortados em pequenos pedaços (cerca $\left.1 \mathrm{kgf} / \mathrm{cm}^{2}\right)$ e então imersos em água destilada na proporção 3:100 (m/v). 


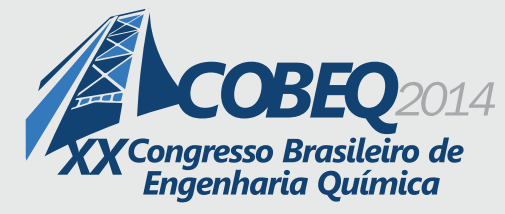

Foram utilizados $12 \mathrm{~g}$ de casulos e $400 \mathrm{~mL}$ de água em erlenmeyers de $1 \mathrm{~L}$. Os mesmos foram fechados com papel filtro preso com cinta plástica, e então colocados em autoclave na pressão manométrica correspondente a $1 \mathrm{kgf} / \mathrm{cm}^{2}$ durante 60 minutos, de acordo com os melhores resultados obtidos por Tomadon Jr. (2011). Após resfriamento, as fibras foram retiradas da solução, que foi então armazenada em garrafa PET e mantida em freezer (em torno de $-20^{\circ} \mathrm{C}$ ) por 24 horas para alcançar precipitação. Após este período, a solução foi retirada do freezer e deixada à temperatura ambiente $\left(25^{\circ} \mathrm{C}\right)$ até descongelar, e então, filtrada a vácuo.

Preparação dos filmes/membranas: os filmes/membranas foram obtidos pelo processo de moldagem convencional aplicado a polímeros termoplásticos e termorrígidos, denominado evaporação, vazamento, ou casting process (Cavalcanti et al., 2002), basicamente, a preparação da solução e aplicação ou espalhamento da mesma em um suporte. Uma solução de sericina com fração mássica de $2 \%(\mathrm{~m} / \mathrm{v})$ foi preparada em água destilada, à temperatura ambiente, já contendo glicerol (0,6g glicerol/g macromolécula), de acordo com os melhores resultados apresentados por Turbiani (2011). A solução foi mecanicamente agitada com agitador equipado com controlador de temperatura a 1000rpm por 1h para obter uma solução homogênea. Em seguida, a temperatura do sistema foi aumentada para $70^{\circ} \mathrm{C}$ e uma solução diluída de dimetiloluréia (DMU) $(0,4 \mathrm{~g}$ glicerol/g macromolécula), de acordo com os melhores resultados apresentados por Turbiani (2011), foi lentamente adicionada à solução biopolimérica. Essa solução foi mantida sob agitação por mais 1 hora. Para filmes/membranas da blenda de sericina e alginato, foi preparada uma solução de igual fração mássica de ambos $(2 \% \mathrm{~m} / \mathrm{v})$, seguindo o mesmo procedimento descrito acima. Da mesma forma para filmes/membranas da blenda de sericina e quitosana, exceto que a quitosana foi solubilizada em solução aquosa de ácido acético $2 \%(\mathrm{~m} / \mathrm{v})$ e o agente reticulante DMU não foi adicionado. Alíquotas de $70 \mathrm{~mL}$ desta solução foram transferidas para placas de polipropileno (diâmetro $=15 \mathrm{~cm}$ ), e levadas à estufa com circulação de ar, a $40^{\circ} \mathrm{C}$ por 24 horas, para formação de um filme/membrana por evaporação. Foram preparados filmes/membranas de cada macromolécula, da blenda da sericina com alginato/quitosana, com adição do glicerol em todas as variações, e glicerol juntamente com DMU (DMU exceto no caso de conter a quitosana).

Caracterização dos filmes/membranas: antes de sua caracterização, os filmes/membranas foram armazenados por 72 horas em dessecadores a uma umidade relativa de 52\% (solução saturada de nitrato de magnésio) e temperatura de $25^{\circ} \mathrm{C}$ para uniformizar seu conteúdo de umidade. Apenas filmes/membranas com boa aparência, avaliados subjetivamente no aspecto visual, foram submetidos à caracterização física. Os filmes/membranas foram caracterizados quanto ao aspecto visual e teor de umidade. A massa inicial de discos cortados dos filmes/membranas $(2,5 \mathrm{~cm}$ de diâmetro) foi quantificada e as amostras submetidas à secagem a $105^{\circ} \mathrm{C}$ por $24 \mathrm{~h}$ em estufa, e a massa seca quantificada novamente. O conteúdo de umidade foi expresso como fração da massa inicial do filme/membrana pela Equação 1 a seguir:

$$
\omega=\frac{\left(\mathrm{m}_{\mathrm{i}}-\mathrm{ms}_{\mathrm{f}}\right)}{\mathrm{m}_{\mathrm{i}}} .100
$$

Onde a $m i$ é a massa seca inicial da amostra em $[\mathrm{g}], m s_{f}$ é a massa seca final da amostra em $[\mathrm{g}]$, 


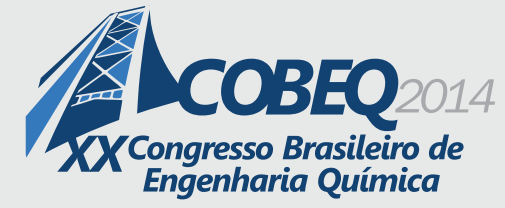

e $\omega$ : umidade do filme (\%).
19 a 22 de outubro de 2014

Florianópolis/SC

\section{RESULTADOS E DISCUSSÃO}

A extração foi realizada em autoclave, já que a mesma é operada com pressão acima da atmosférica, acarretando um aumento do ponto de ebulição da água, e pressão constante, já que não há perda de vapor durante o processo. Assim, na pressão manométrica de $1 \mathrm{kgf} / \mathrm{cm}^{2}$, a temperatura corresponde a $120^{\circ} \mathrm{C}$. Essas duas variáveis, pressão e temperatura, auxiliam na velocidade de solubilização da sericina em água, e, consequentemente, aumento da porcentagem de sericina extraída. É possível afirmar que utilizar somente água como solvente é suficiente para retirar uma grande porcentagem de sericina presente nos casulos, ou seja, obter um bom rendimento na etapa.

Através da precipitação por congelamento, foram obtidos bons rendimentos, não sendo preciso utilizar qualquer agente químico, o que dispensa outro processo para remoção do mesmo. $\mathrm{O}$ rendimento do processo de extração de sericina alcançou $66 \%$ em relação aos $38 \%$ de sericina presentes nos casulos, sendo então um rendimento, com as perdas, em torno de $25 \%$. A perda de sericina no processo de filtração é em torno de $9 \%$. Logo, pode-se dizer que a eficiência final do processo de extração é em torno de $23 \%$, compatível com os resultados obtidos por Kurioka et al. (2004).

A concentração final da sericina obtida foi quantificada por diferença de massa de três alíquotas de $1 \mathrm{~mL}$ em placas de petri, levadas à estufa a $105^{\circ} \mathrm{C}$ por 24 horas. A concentração final depende do tempo da filtração. Quanto maior o tempo, mais concentrada fica a sericina, porém, há formação de uma torta e parte da sericina fica presa ao papel filtro.

A Tabela 1 apresenta as composições das membranas produzidas e as porcentagens de umidade presente em cada uma delas.

Tabela 1 - Composições das membranas e porcentagens de umidade

\begin{tabular}{|c|c|c|}
\hline Filme/Membrana & Composição & \% umidade \\
\hline A & $\mathrm{A}+\mathrm{G}+\mathrm{D}$ & 20,6 \\
\hline $\mathrm{B}$ & $\mathrm{Q}+\mathrm{S}+\mathrm{G}$ & 30,5 \\
\hline $\mathrm{C}$ & $\mathrm{A}+\mathrm{S}+\mathrm{G}$ & 18,3 \\
\hline $\mathrm{D}$ & $\mathrm{A}+\mathrm{S}+\mathrm{G}+\mathrm{D}$ & 20,9 \\
\hline $\mathrm{E}$ & $\mathrm{A}+\mathrm{G}$ & 20,1 \\
\hline F & $\mathrm{A}$ & 18,0 \\
\hline $\mathrm{G}$ & $\mathrm{Q}+\mathrm{G}$ & 43,2 \\
\hline $\mathrm{H}$ & $\mathrm{Q}$ & 16,5 \\
\hline
\end{tabular}




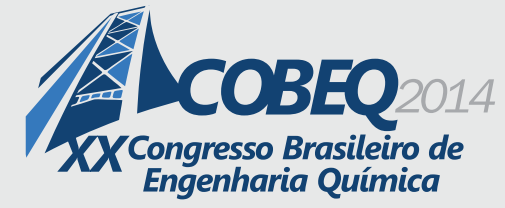

Sendo A: alginato, D: DMU e G: glicerol.
19 a 22 de outubro de 2014

Florianópolis/SC

Quanto ao aspecto visual, foram verificadas as seguintes características: continuidade, a ausência de ruptura ou fraturas após a secagem; homogeneidade, a ausência de partículas insolúveis, bolhas visíveis a olho, regiões com opacidade ou cores diferentes; e manuseabilidade, possibilidade de manipulação sem que haja ruptura.

Os filmes/membranas confeccionados com alginato são transparentes, de fácil desprendimento do suporte, contínuos e homogêneos (definido como F). Porém, somente com a adição dos agentes plastificante e reticulante é que os filmes/membranas possuem flexibilidade, plasticidade, boa manuseabilidade, sendo razoavelmente sensíveis (definidos como A e E). A umidade dos filmes/membranas produzidos com o alginato varia de 18,3 a 20,9\%, respectivamente.

Os filmes/membranas confeccionados com quitosana são bastante amarelados, porém com certa transparência, de fácil desprendimento do suporte, contínuos e homogêneos (definido como H). Porém, somente com a adição do agente plastificante é que os filmes/membranas possuem flexibilidade, plasticidade, boa manuseabilidade (definido como $\mathrm{G}$ ). $\mathrm{O}$ mesmo possui o maior valor de umidade de $43,2 \%$. A umidade dos filmes/membranas com quitosana é relativamente alta, variando de 30,5 a $43,2 \%$.

A utilização da blenda da sericina com alginato/quitosana confere maior resistência aos filmes/membranas confeccionados. Os filmes/membranas confeccionados com sericina e adição dos agentes plastificante e/ou reticulante, definidas como membranas $\mathrm{B}, \mathrm{C}$ e $\mathrm{D}$, são levemente amareladas (exceto a B que contem quitosana), transparentes, e todas de fácil desprendimento do suporte, contínuas, homogêneas e com boa manuseabilidade.

A adição do glicerol confere maior flexibilidade aos filmes/membranas confeccionados, porém, os mesmos ficam frágeis no momento de manipulação e retém maior umidade, como podese observar nos filmes/membranas A/E e H/G.

\section{CONCLUSÕES}

A adição de glicerol permite aos filmes/membranas um maior alongamento, porém, ao manipulá-los, nota-se uma diminuição na resistência dos mesmos. Esse comportamento sugere que moléculas de glicerol enfraquecem as forças intermoleculares entre as cadeias, aumentando a mobilidade das cadeias dos polímeros e o volume livre do sistema, e em consequência, facilitando a absorção de água, aumentando o teor de umidade dos filmes/membranas.

As membradas confeccionadas com quitosana retém maior umidade em relação às membranas com alginato. 
Ao contrário do efeito observado pela utilização do glicerol, a incorporação de DMU diminui a capacidade de alongamento dos filmes/membranas, e, ao manipulá-los, nota-se um aumento na resistência dos mesmos, resultante de ligações cruzadas dentro e entre as cadeias das macromoléculas utilizadas.

É notável a maior resistência dos filmes/membranas confeccionados com a blenda dos polímeros (sericina/alginato, sericina/quitosana) utilizados no trabalho, conferindo aos mesmos continuidade, homogeneidade e manuseabilidade.

\title{
5. NOMENCLATURA
}

\author{
A: alginato \\ D: DMU \\ G: glicerol \\ $\mathrm{m}_{\mathrm{i}}$ : massa seca inicial da amostra $(\mathrm{g})$ \\ $\mathrm{m}_{\mathrm{sf}}$ : massa seca final da amostra $(\mathrm{g})$ \\ Q: quitosana \\ S: sericina \\ $\omega:$ umidade do filme $(\%)$
}

\section{REFERÊNCIAS}

CAVALCANTI, O. A.; VAN DEN MOOTER, G.; CARAMICO-SOARES, I.; KINGET, R. Polysaccharides as eccipientes for colon-specific coatings. Permeability and swelling properties of casted films. Drug Dev. Ind. Pharm., New York, v.28, n. 2, p. 157-164, 2002.

CHEN X et al. Molecular Affinity and Permeability of Different Molecular Weight Chitosan Membranes. J Agric. Food Chem 2002.

GIMENES, M. L.; LIU, L.; FENG, X. Sericin/PVA blend membranes for pervaporation separation of ethanol/water mixtures. Journal of Membrane Science, v. 295, p. 71-79, 2007.

KONGDEE, A.; BECHTOLD, T.; TEUFEL, L. Modification of Cellulose Fiber with Silk Sericin. J. App. Pol. Scie., v. 96, p.1421-1428, 2004.

KURIOKA, A.; KURIOCA, F.; YAMAZAKI, M. Characterization of sericin powder prepared from citric acid-degraded sericin polypeptides of the silkworm, Bombyx mori. Biosci. Biotechnol. Biochem., v. 68 (4), p. 774-780, 2004.

OLIVEIRA, A. P. C. Produção e caracterização de partículas de hidrogéis para aplicações em cosméticos. (2004). 158 f. (Mestrado em Engenharia Química) - Faculdade de Engenharia Química, Universidade Estadual de Campinas, Campinas, 2004. 
RABELLO, M. Aditivação de polímeros. São Paulo: Artliber, 2000. 242 p.

RINAUDO, M. Main properties and current applications of some polysaccharides as biomaterials. Polymer International, v. 57, n. 3, p. 397-430, 2008.

SCOTT, G. “Green” polymers. Polymer Degradation and Stability, v. 68, p. 1-7, 2000.

TOMADON JR., J. Obtenção da protéina sericina com alta massa molecular, a partir de casulos Bombyx mori. Dissertação (Mestrado em Engenharia Química). Universidade Estadual de Maringá, Maringá - PR, 2011.

TURBIANI, F. R. B. Desenvolvimento e caracterização de filmes biodegradáveis de sericina e PVA reticulados com dimetiloluréia. Dissertação (Doutorado em Engenharia Química). Universidade Estadual de Maringá, Maringá - PR, 2011.

WIEBECK, H.; HARADA, J. Plásticos de engenharia. São Paulo: Artliber, 2005. 349p

WU, J.; WANG, Z.; XU, S. Preparation and characterization of sericin powder extracted from silk industry wastewater. Food. Chem., v. 103, p. 1255-1262, 2007.

ZACTITI, E. M. Desenvolvimento e caracterização de filmes biodegradáveis de alginato de cálcio sem e com sorbato de potássio, Tese de Doutorado. Campinas: Faculdade de Engenharia Química, Universidade Estadual de Campinas, 2004.

ZHANG, Y. Applications of natural silk protein sericin in biomaterials. Biotechnol. Adv. v. 20, p. 91-100, 2002. 